\title{
A GESTÃO INSTITUCIONAL DOS CURSOS PROFISSIONAIS TÉCNICOS DE NÍVEL MÉDIO NA MODALIDADE A DISTÂNCIA OFERTADOS PELA REDE E-TEC BRASIL: PRIMEIRAS APROXIMAÇÕES*
}

\author{
Clovis Nicanor Kassick \\ Universidade Federal de Santa Catarina, Florianópolis, Santa Catarina, \\ Brasil \\ José SeVERINo Bento \\ Instituto Federal de Educação, Ciência e Tecnologia de Pernambuco, \\ Recife, Pernambuco, Brasil \\ Paulo Ricardo Santos Dutra \\ Universidade Federal Rural de Pernambuco, Recife, \\ Pernambuco, Brasil
}

\begin{abstract}
Resumo: Desde a última década, o Brasil tem realizado um grande investimento na modalidade de educação a distância. Em 2007, foi criada a Escola Técnica Aberta do Brasil, que oferece Cursos Profissionais Técnicos de Nível Médio na modalidade EaD. A questão colocada por esta pesquisa, de caráter exploratório, tendo como instrumentos a análise documental e questionários aplicados via web a 385 gestores desses cursos, foi saber como está ocorrendo a gestão no processo de implantação e desenvolvimento desses cursos. Este trabalho apresenta os resultados parciais que apontam as principais dificuldades na gestão: carência de recursos humanos (60,8\%), de apoio pedagógico (43,4\%), de estrutura física (34,7\%), de recursos financeiros (30,4\%), bem como a institucionalização dos polos $(21,7 \%)$, entre outros (o questionário admitia múltiplas respostas). A pesquisa aponta, ainda, algumas das medidas necessárias à consolidação e qualificação da Educação Profissional Técnica de Nível Médio, na modalidade a distância.

PALAVRAS-CHAVE: Currículo referência. Educação profissional. Educação a distância.
\end{abstract}

\footnotetext{
* Artigo recebido em 5/3/2014 e aprovado em 15/6/2014.
} 
INTRODUÇÃO

A educação a distância $(\mathrm{EaD})$ é uma modalidade educacional em que a produção do conhecimento acontece sem a necessidade dos espaços formais da sala de aula, ocorrendo em tempos e locais distintos entre o educador e o educando. Desde a última década, o Brasil tem realizado um grande investimento nessa modalidade de ensino e, atualmente, a EaD é um programa de governo na formação de profissionais de nível técnico e superior que objetiva interiorizar uma educação de qualidade nas regiões mais remotas desse extenso país. Outro importante papel dessa modalidade de educação é garantir o cumprimento de políticas inclusivas, por meio das quais aqueles que residem fora dos grandes centros urbanos tenham garantido seu direito de realizar cursos técnicos e/ou superiores nas grandes instituições públicas do país.

Desse modo, parcerias entre os governos federal, estadual e municipal e as instituições federais de ensino têm expandido a educação a distância em todo o país. Em 2006, foi criada, no âmbito do Ministério da Educação (MEC), a Universidade Aberta do Brasil (UAB), com o objetivo de interiorizar e expandir a educação superior no país. Formatada em convênio com instituições de ensino superior e governos municipais, a UAB foi implementada em todos os estados brasileiros, e a adesão ao programa foi tamanha que o governo decidiu, em 2007, criar a escola Técnica do Brasil (e-Tec Brasil), programa de cursos técnicos de nível médio a distância, também em regime de colaboração da União com os estados, municípios e instituições públicas de ensino. A EaD ofertada pela União está organizada de forma que cada instância parceira, na implementação do programa, tenha suas atribuições, no pressuposto de que o bom funcionamento em conjunto dessas ações irá garantir o sucesso do programa.

Nessa parceria, à União cabe repassar os recursos às instituições de ensino, a quem compete a aquisição de bens para o funcionamento dos cursos, a administração dos recursos, a contratação de professores e a responsabilidade de todo o processo administrativo e pedagógico. Aos estados e municípios cabe a responsabilidade da estrutura física e apoio administrativo.

Nesse cenário, o presente trabalho relata e analisa resultados parciais da pesquisa realizada, cujo objeto foi a gestão institucional empreendida pelas diferentes instituições federais que constituem a Rede Federal de Educação Profissional e Tecnológica e ofertam cursos na modalidade EaD para a Rede e-Tec Brasil em diferentes regiões do país. $\mathrm{O}$ estudo partiu do pressuposto de que não existem normas e procedimentos para a institucionalização 
de cursos em EaD, o que tem gerado grande demanda de retrabalho para todas as equipes que compõem o sistema em função de deficiências na operacionalização dos procedimentos necessários e falhas de comunicação entre os gestores do MEC, das instituições ofertantes, dos municípios-polo, bem como pela falta de estudos de viabilidade gerencial.

Assim, o estudo teve como objetivo geral diagnosticar a situação de implantação e implementação de cursos técnicos em EaD nas diversas instituições existentes no país. Como objetivos específicos, buscou-se relacionar quais instituições oferecem cursos na modalidade EaD para a Rede e-Tec Brasil, bem como localizar geograficamente as instituições ofertantes de cursos, listar os cursos ofertados, quantificar o número de alunos matriculados nos cursos e instituições, identificar o estágio de desenvolvimento dos cursos, além de listar, pontuar e analisar as principais dificuldades apresentadas no processo de implantação dos cursos.

O procedimento metodológico adotado para o levantamento do estado da arte, no que concerne à gestão institucional dos cursos, valeu-se dos projetos pedagógicos dos cursos e de questionário que foi enviado via e-mail institucional a 43 coordenadores gerais das instituições, 136 coordenadores de curso e 206 coordenadores de polo. Dos questionários enviados, 56,4\% foram preenchidos e devolvidos, passando a representar $100 \%$ do universo da pesquisa. Os dados coletados foram compilados em um editor de planilhas e, a partir deles, as variáveis foram descritas por tabelas de frequências absolutas e relativas. Foram construídas tabelas de frequência separando os resultados por regiões brasileiras quando o número amostral permitiu; em alguns casos, o número de categorias era maior que o número de respondentes para cada categoria, o que inviabiliza, segundo Leme (1967), a análise em separado.

Para as variáveis contínuas (numéricas), as medidas de tendência central e de dispersão utilizadas foram a média aritmética $(\bar{x})$ mais ou menos o desvio-padrão $(s)$, apresentados no formato $\bar{x} \pm s$, ou, no caso de valores merísticos (não decimalizáveis), a mediana (Me) com os quartis inferior (Q1) e superior (Q3). Em variáveis categóricas, a moda foi usada como medida de tendência central, representando a categoria mais frequente na amostra (LEVIN, 1978).

Os principais resultados aqui analisados referem-se ao modo como se define a oferta de cursos, as necessidades mais emergentes e recomendações básicas para a sequência da organização e implementação da rede enquanto garantia de democratização e interiorização da educação profissional técnica de nível médio através da modalidade a distância e como política inclusiva dos até então excluídos. 
Sobre a EAD no BrasiL

Não é nova a proposta de ensino a distância no Brasil e diferentes programas já foram implantados baseados em experiências de outros países. De acordo com Moraes et al. (2007), a EaD no Brasil teve início em 1923 com a fundação da Rádio Sociedade do Rio de Janeiro, a qual transmitia programas de radiotelegrafia e telefonia, línguas e outros. Ainda em Moraes et al. (2007), são citadas as experiências radiofônicas do Projeto Minerva (1939) e a criação do Instituto Universal Brasileiro em 1941, este com cursos técnicos e profissionalizantes por correspondência e ainda em atuação.

Mais recentemente, em maio de 1996, foi criada, através do Decreto n. 1.917/96, no âmbito do MEC, a Secretaria de Educação a Distância (SEED) (BRASIL, 1996). Entre as ações dessa secretaria, estava a TV Escola e o Programa Nacional de Informática na Educação (Proinfo), ambas com o objetivo de assistir a educação presencial de estrutura de Tecnologia da Informação. A Lei de Diretrizes e Bases da Educação Nacional (LDB), Lei n. 9.394/96 (BRASIL, 1996), em seu artigo 80, determina que o poder público incentivará o desenvolvimento e a veiculação de programas de ensino a distância em todos os níveis e modalidades de ensino e da educação continuada, o que só foi regulamentado em dezembro de 2005, através do Decreto n. 5.622/05. A regulamentação caracteriza a EaD como modalidade educacional na qual a mediação didático-pedagógica ocorre com a utilização de meios e tecnologias de informação e comunicação, com estudantes e professores em lugares ou tempos diversos (BRASIL, 2005). O decreto também define parâmetros para sua metodologia, gestão e avaliação, determinando a obrigatoriedade de momentos presenciais para as avaliações, estágios, defesas de trabalhos de conclusão de curso e atividades de laboratórios, quando necessário.

Além dessas e de outras ações desenvolvidas no âmbito da SEED/ MEC, em junho de 2006, através do Decreto n. 5.800/06, foi instituída a UAB (BRASIL, 2006), que tem como finalidade o desenvolvimento da EaD com a expansão e interiorização de ofertas de cursos de nível superior no país. Entre seus objetivos, está a ampliação do acesso à educação pública superior, redução das desigualdades de oferta de cursos superiores nas diferentes regiões do país e fomento ao desenvolvimento institucional da EaD. No artigo $2^{\circ}, 0$ decreto determina que os cursos devam ser desenvolvidos por instituições públicas de ensino superior em articulação com os polos de apoio presencial.

O referido decreto define Polo de Apoio Presencial como a unidade operacional para o desenvolvimento descentralizado de atividades pedagógicas e administrativas relativas aos cursos e programas ofertados a distância. No parágrafo $2^{\circ}$ do art. $2^{\circ}$, afirma: "os polos de apoio presencial deverão 
dispor de infraestrutura e recursos humanos adequados às fases presenciais dos cursos e programas do sistema UAB". No art. 4', o decreto responsabiliza, de forma compartilhada, os entes federados a firmarem acordos formais e assumirem a manutenção dos polos.

Com o sucesso de adesão à nova forma de interiorização da educação superior, em 12/12/2007, através do Decreto n. 6.301, foi criado o Sistema Escola Técnica Aberta do Brasil, o qual tinha como finalidade o desenvolvimento da educação profissional técnica na modalidade de educação a distância, ampliando a oferta e democratizando o acesso aos cursos técnicos gratuitos em instituições públicas (BRASIL, 2007). Baseado na UAB, o Sistema determinava que, para o alcance dos objetivos, contava com a colaboração da União, estados e municípios. Em outubro de 2011, foi instituída, através do Decreto n. 7.589, em substituição a esse sistema, a Rede e-Tec Brasil, "com a finalidade de desenvolver a educação profissional e tecnológica na modalidade de educação a distância, ampliando e democratizando a oferta e o acesso à educação profissional pública e gratuita no País" (BRASIL, 2011).

\section{A INSTITUCIONALIZAÇÃO DA EDUCAÇÃO NA MODALIDADE A DISTÂNCIA}

No ensino presencial ou na EaD, a gestão institucional é complexa, envolvendo diferentes níveis de articulação, diferentes campos de conhecimentos, diferentes saberes e exigindo de todos os envolvidos trabalho em conjunto com o objetivo de formar integralmente o ser humano. Na gestão do Programa e-Tec Brasil, fundamentado no tripé do trabalho colaborativo de três entes, conforme já referido, os processos gerenciais ficam mais complexos e burocratizados ainda, tendo em vista que o gestor institucional responde pelo funcionamento de todo o curso, desde a avaliação dos polos presenciais nos municípios, a formatação dos cursos, a seleção dos alunos, a produção do material didático, a assistência ao aluno, até a gestão financeira e todo o processo pedagógico, ou seja, planejamento, acompanhamento e controle.

De acordo com Moore (2007), a educação a distância é um sistema complexo, composto por um conjunto de subsistemas capazes de intermediar o processo de ensino aprendizagem, no qual "todos estão agindo e interagindo, em todo o processo" (p. 11). Nessa perspectiva, os subsistemas de criação, implementação e avaliação são importantes para a manutenção da qualidade do programa.

Para Moraes et al. (2007, p. 16), a gestão institucional da EaD deve ser pautada na autonomia e na organização dos procedimentos e controle para evitar a fragmentação de ações dos gestores locais e, consequentemente, a perda do controle dos processos: 
Um processo de gestão e autonomia requer, pois, clareza em seus propósitos, em seus princípios, em suas políticas, das quais decorrem as regulamentações que orientam a elaboração e a implementação dos projetos. Rege o exercício da autonomia, em uma ação educativa, planejamento, direção, acompanhamento, avaliação e controle das ações. Em EaD, essas questões precisam estar contempladas nas políticas institucionais, expressas no Plano de Desenvolvimento Institucional - PDI, e serem definidas no plano estratégico, em seus objetivos, metas, ações e organizadas em projetos executáveis.

A EaD não pode ser conduzida à sombra do ensino presencial, servindo-se de suas políticas institucionais, suas metas e seus procedimentos. A EaD precisa ser incorporada à instituição como uma nova forma de fazer educação, com novas técnicas, nova organização dos espaços, novos processos pedagógicos, procedimentos específicos, infraestrutura definida, equipe capacitada e o desejo de iniciar cursos para atender aos mais diferentes perfis de alunos.

Para Corrêa (2007) e Moore (2007), a mediação entre estudantes e educadores é a principal característica da EaD. Segundo esses autores, a proposta didática precisa ser definida a partir do desenho do curso e sustentada por uma coordenação pedagógica que evite desvios, tendo em vista, principalmente, que a prática docente e a formação de professores no Brasil estão fundamentadas no ensino presencial. Por isso, professores e gestores, durante sua formação, aprendem sobre docência e gestão do ensino presencial e nada sobre a modalidade EaD.

Quanto às dificuldades da EaD, Corrêa (2007, p. 12) escreve:

[...] os cursos de EaD convivem com alguns desafios em relação ao desenvolvimento e a gestão dos sistemas de EaD. Incluem-se aí a formação e o acompanhamento da tutoria, a definição de estratégias adequadas para o serviço de apoio, a avaliação da qualidade do ensino, a convivência com instituições mistas e a escolha pela manutenção dos centros locais ou pela centralização do apoio.

Já para Pereira (2007), um dos grandes desafios da gestão da EaD está em escolher corretamente os meios técnicos, considerando as tecnologias mais adequadas à acessibilidade do público-alvo. Quanto à formação dos professores e sua postura, afirma ele, a EaD exige uma nova prática, com novas competências para o professor, dentre elas:"saber lidar com os ritmos individuais de seus alunos; apropriar-se de novas técnicas de elaboração de material didático, ter domínio de certas técnicas de avaliação, trabalhar em ambientes diversos daqueles do presencial e desenvolver habilidades de investigação com técnicas variadas" (PEREIRA, 2007, p. 90). 
O planejamento, a avaliação, o formato das atividades, o tempo necessário aos atendimentos on-line, as reuniões com os tutores, a preparação do material impresso, a adaptação à web e videoconferência requerem dos formadores o aprendizado de uma nova forma de fazer educação; requerem dedicação, capacitação continuada e planejamento detalhado de cada semana de aula.

Os procedimentos para implantação de cursos em EaD requerem determinação política da instituição, expressa no PDI; formação de equipe especializada, com gestores, conteudistas, formadores, tutores, designer instrucional, revisores, diagramadores; construção de procedimentos e planos de cursos específicos; delimitação de espaço físico e infraestrutura de tecnologia da informação bem como garantia de orçamento. De acordo com Moore (2007), como os cursos da educação a distância são transmitidos por tecnologias, os materiais do curso devem ser elaborados por especialistas de áreas diferentes, visto a necessidade de preparar material para diferentes mídias e com linguagem acessível a diferentes públicos, sem perda de conteúdo ou qualidade na aprendizagem.

Esse conjunto de condições é essencial, sobretudo para a instauração de uma nova "arquitetura organizacional"1 do processo educativo, alicerçado nas características próprias da $\mathrm{EaD}$, em que os actantes ${ }^{2}$ da mediação pedagógica precisam estar balizados pela concepção pedagógica relacional como elemento fundamental para a construção do conhecimento, cujo pressuposto epistemológico é a relação sujeito-objeto. ${ }^{3}$

Becker (1993), ao explicitar esse paradigma epistemológico, realça a importância de que a organização do processo educativo esteja fundamentada na oportunidade que o professor oferece ao estudante, pela forma como organiza a sua ação didática, de se relacionar com o objeto de conhecimento. Segundo ele, "o aluno só aprenderá alguma coisa, isto é, construirá algum conhecimento novo, se ele agir e problematizar a sua ação" (BECKER, 1993, p. 92). Ou seja, o professor acredita que o conhecimento só é possível a partir de duas condições: a primeira, que o estudante aja sobre o material que o professor presume que tenha algo de cognitivamente interessante e significativo e, por essa razão, desafia-o para a apreensão daquele conhecimento específico; a segunda, que o estudante responda para si mesmo sobre as perturbações provocadas pela assimilação do conhecimento novo, isto é, que reflita sobre o novo, no momento de sua assimilação, o que ocorrerá a partir das questões levantadas pelos próprios estudantes e, principalmente, pelo professor.

Assim, retoma-se a maiêutica socrática no fazer e pensar a organização didática do professor quando se afirma que professor não é aquele que 
ensina, mas aquele que pergunta, como bem o demonstra a declaração de Piaget (1988, p. 154): "[...]cada vez que ensinamos algo ao aluno, impedimos que ele invente por si mesmo". Dessa forma, o pressuposto básico é que o conhecimento é uma construção contínua que o sujeito é capaz de realizar a partir das relações que estabelece com o objeto de conhecimento.

Portanto, o conhecimento (não a informação) é fruto da experiência pessoal e subjetiva e se caracteriza pela formação de novas estruturas mentais que não existiam anteriormente no indivíduo. Essa é a razão para afirmar-se que o conhecimento humano é essencialmente ativo. Para Piaget (1977, p. 30),

[...] conhecer um objeto é agir sobre e transformá-lo, apreendendo os mecanismos dessa transformação vinculados com as ações transformadoras. Conhecer é, pois, assimilar o real às estruturas de transformações, e são as estruturas elaboradas pela inteligência enquanto prolongamento direto da ação.

Para ele, o conhecimento é fruto de duas etapas: uma exógena, que é a fase da constatação, da cópia, da repetição e reprodução das informações do meio; e outra endógena, quando as informações são processadas, compreendidas em suas inter-relações e combinações, o que se dá por meio da análise, das comparações, da crítica e da criatividade e inventividade de readequá-las às novas situações.

Deve-se considerar que a aprendizagem pode parar na primeira fase do conhecimento, isto é, ficar na pura e simples repetição informacional. 0 verdadeiro conhecimento implica na fase endógena, ou seja, na reelaboração da informação, constituindo-a em conhecimento pela reestruturação mental que o indivíduo é capaz de realizar.

Sobre isso, Chiarottino (1980, p. 82), valendo-se de estudos de Piaget, afirma:

As estruturas orgânicas (estruturas mentais) que constituem a inteligência não são nem inatas nem determinadas pelo meio, mas são o produto de uma construção, devido às perturbações do meio e à capacidade do organismo de ser perturbado e de responder a esta perturbação. É através das ações do indivíduo, a partir dos esquemas motores, que se dá a compensação a essas perturbações, ou seja, a troca do organismo com o meio, graças a um processo de adaptação progressivo no sentido de uma constante equilibração que permite a construção de estruturas específicas para o ato de conhecer.

Decorrente desse paradigma epistemológico, há que se explicitar e compreender todo um conjunto de princípios, valores e conceitos para que a pedagogia relacional (cognitivista) efetive-se, sobretudo tratando-se de educação na modalidade EaD. 
Essa pedagogia possui como característica geral o fato de fundamentar-se nas relações, sejam interpessoais, sejam do sujeito com o objeto de conhecimento, isto é, a forma como o indivíduo "inter-age" com a realidade para conhecê-la. Logo, a mediação pedagógica necessita ser eminentemente investigativa e estar centrada na capacidade do estudante em processar e integrar as informações para constituí-las (transformá-las) em conhecimento.

As consequências, para a educação, dessa concepção de desenvolvimento do sujeito e da construção do conhecimento são primordiais. O processo educacional e, mais especificamente, a forma de organizá-lo e conduzi-lo, ou sua arquitetura organizacional, exige profundas transformações na habitual forma de ser do professor e do estudante.

O professor passa a ser agente desequilibrador, desafiador e problematizador das ações dos estudantes, que, por sua vez, devem abandonar sua posição de alunos (aquele que é sem luz e que só repete) para constituírem-se em estudantes, em investigadores de suas realidades e entornos sociais, em sujeitos de seu próprio processo de aprendizagem de tal forma que, ao buscar o novo ponto de equilíbrio, ao responder aos desafios e ao solucionar os problemas, possam construir-se, construindo novas estruturas de pensamento.

Assim, podemos melhor entender que o objetivo da educação não deve ser a "transmissão" de verdades pré-estabelecidas, de informações, de demonstrações, de reprodução de modelos, mas sim que o estudante aprenda, pela reflexão, a conquistar essas verdades, ainda que isso implique em tateios experimentais.

Para Freire (1974, p. 42), a ausência dessa reflexão implica a adoção de métodos educativos e diretrizes didáticas que reduzem o homem à condição de objeto em vez de sujeito. Afirma ele:

É preciso que a educação esteja, em seu conteúdo, em seus programas e em seus métodos, adaptada aos fins que persegue: permitir o homem a chegar a ser sujeito, construir-se como pessoa, transformar o mundo e estabelecer com os outros homens relações de reciprocidade, fazer a cultura e a história.

Assim, o objetivo básico da educação deve ser o de provocar e criar condições para que o sujeito desenvolva uma atitude de reflexão crítica.

Nessa perspectiva, a educação, em especial na modalidade a distância, independente se de educação básica ou superior; necessita desenvolver ações motoras, verbais e mentais, ou, dito de outra forma, necessita desenvolver o saber-fazer, o saber-ser e o saber-saber. Para tanto, precisa organizar-se didaticamente para possibilitar que a ação do estudante seja uma ação investigativa. Isso implica que a ação didática seja 
organizada no sentido de criar necessidades (problemas) para que, uma vez instaladas, promovam a motivação intrínseca do estudante para satisfazê-las, provocando a capacidade de apreender ${ }^{4}$ e tornando possíveis a criação e o desenvolvimento das estruturas mentais do ponto de vista endógeno.

Conforme Chiarottino (1980, p. 98),

se o indivíduo construiu suas estruturas do ponto de vista endógeno, estas terão necessidades de 'alimento', isto é, necessidade dos objetos que podem assimilar. Dizer que um sujeito se interessa por um resultado ou por um objeto, significa que ele pode assimilá-lo ou que ele antecipa uma assimilação, e dizer que tem necessidade de algo, significa que possui estruturas exigindo a sua utilização.

De tudo que se disse até aqui, fica claro que o processo de mediação pedagógica é o momento em que as concepções devem se concretizar. Logo, a centralidade está na relação estabelecida entre os actantes, para que estes favoreçam que o estudante desenvolva as estruturas mentais de pensamento que lhe possibilitarão o saber-fazer, o saber-ser e o saber-saber ou, em síntese, o aprender a apreender.

Essa arquitetura organizacional valoriza a ação, a atividade do estudante sobre o objeto de conhecimento. É importante lembrar que a ação, a atividade aqui referida, não se reduz à ação ou atividade motora, apenas a inclui quando for o caso. Cabe novamente recorrer a Piaget (1988, p. 166), quando esclarece que o termo "atividade" pode ter um significado tanto reflexivo e puramente gnóstico quanto prático e manual baseado no interesse e designando uma operação exterior e motora, sendo que o primeiro significado é que interessa à educação. Para ele, "[...] pode-se ser ativo em puro pensamento" e, continua, se o conceito de ativo, enquanto sinônimo de ações concretas do sujeito

...é verdadeiro para os graus elementares, não o é, entretanto, para os níveis superiores, onde o aluno pode ser inteiramente ativo, no sentido de uma redescoberta pessoal de verdades a conquistar, fazendo com que esta atividade incida sobre a reflexão interior e abstrata. (op. cit., p. 78)

Portanto, uma mediação pedagógica que procura desenvolver a inteligência deverá priorizar a atividade do sujeito considerando-o inserido numa situação social, pois apreender significa assimilar o objeto a esquemas mentais.

Considerando as diversidades e singularidades dos diferentes sujeitos, a mediação pedagógica precisa, igualmente, assumir formas diversas no decurso de seu desenvolvimento, já que o "como" o estudante apreende 
a realidade depende dos esquemas, das estruturas mentais de cada um e da forma pela qual ele se relaciona com o objeto de conhecimento, razão para que essa organização se estruture na investigação, na busca da solução de problemas que a pesquisa possibilita, e não na fixação de fórmulas, nomenclaturas, classificações, definições e repetições de informações.

Nessa perspectiva, se o papel do professor é o de problematizar, desequilibrar e/ou mediar, o do estudante é o de pesquisar, investigar. Professor e estudante interagem com o objeto de conhecimento através do diálogo realizado via tecnologias estabelecidas. A dialogicidade é o instrumento mais adequado para a investigação da realidade.

O diálogo sobre a realidade tem por objetivo não só entendê-la mas também, e fundamentalmente, questioná-la: Por que ela é assim? Por que se constituiu dessa forma? De quais outras formas poderia ser constituída? Que elementos precisariam existir para que a construção dessa realidade fosse diferente? Não podemos esquecer que é o diálogo questionador sobre o real que possibilita ao conhecimento avançar pelas alternativas de soluções propostas a um mesmo problema.

Para tanto, a mediação pedagógica deve alicerçar-se na teoria dialética do conhecimento. Devemos ter presente que a realidade é contraditória e, para superá-la, é necessário compreender a relação entre os elementos que a constituem e por quais razões ela está constituída dessa forma e não de outra.

Nesse sentido, é necessário entender que a primeira visão que o sujeito tem da realidade é sincrética, isto é, o real se apresenta aos nossos olhos, num primeiro momento, em seu todo, de forma confusa e indistinta. Para que possamos compreendê-lo e termos sobre ele uma relação e ação conscientes, devemos analisar não só suas partes, os elementos que o constituem, mas sobretudo a forma como essas partes e elementos se inter-relacionam para compor o todo. Para que isso ocorra, é necessário que os estudantes desenvolvam a capacidade de identificar, observar, comparar, classificar, interpretar, criticar, relacionar, sintetizar, avaliar e transferir conhecimentos em novas situações. Isso porque esses são os instrumentos que lhes permitirão olhar analítica e criticamente o real para sair da visão sincrética e chegar à visão de síntese que os torna capazes de explicar e compreender o todo de forma clara e sistemática, com plena compreensão das partes que o constituem - o que, em decorrência, lhes permitirá uma ação consciente e efetiva sobre o real com vistas a sua transformação e/ou readequação.

Considerando os pressupostos acima, passamos à apresentação e análise dos dados levantados junto aos gestores de cursos da Rede e-Tec Brasil. 
ANÁLISE PRELIMINAR DOS DADOS

O questionário enviado aos gestores compreendia um conjunto de setenta e cinco perguntas assim distribuídas: trinta e uma para o coordenador geral; vinte e sete para o coordenador de curso e dezessete para coordenadores de polo. Neste relato, apresentamos e analisamos as respostas dadas às questões referentes especificamente à decisão pela oferta $\mathrm{e}$ divulgação de cursos; dificuldades em sua implantação; procedimentos legais e elaboração do projeto pedagógico do curso; procedimentos no processo de seleção de recursos humanos; e avaliação institucional das ações.

\section{Coordenador geral}

Participaram da pesquisa 23 coordenadores gerais e-Tec das cinco regiões brasileiras. Inquiridos sobre questões referentes à gestão do sistema e-Tec Brasil em sua instituição, os coordenadores demonstraram conhecer sua realidade e preocupação com a situação em que se encontram. Quando perguntados sobre a decisão de oferta de cursos, os coordenadores poderiam assinalar mais de uma opção e $73,9 \%$ responderam que realizam pesquisa de mercado para embasar a oferta, 65,2\% atendem à solicitação dos municípios/estado e $56,5 \%$ consideram o planejamento interno da instituição para expansão dos cursos no estado, enquanto apenas $8,7 \%$ responderam que consideram também o arranjo produtivo local. Considerando que a expansão dos cursos ocorre face a uma demanda de mercado regional e que aproximadamente $73,9 \%$ dos coordenadores afirmaram realizar pesquisa de mercado, podemos concluir que os cursos ofertados estão em sintonia com as necessidades do mercado, logo, cumprindo o seu propósito de formação de mão de obra especializada para a sua região.

Sobre as dificuldades encontradas na instituição para a implantação de cursos em EaD, era possível assinalar mais de uma alternativa. A falta de recursos humanos totalizou $60,8 \%$ das respostas; falta de apoio pedagógico, 43,4\%; falta de estrutura física, 34,7\%; falta de recursos financeiros, 30,4\% e falta de formalização institucional com os polos $21,7 \%$. Esses resultados revelam a dificuldade do gestor institucional em realizar um trabalho com planejamento, eficiência e qualidade, conforme referido na literatura, dada a falta de estrutura física, pessoal, procedimentos formais e atos de legalização dos processos.

Quanto à formalização de procedimentos e a juntada de documentos legais para a construção do PPC (Projeto Pedagógico de Curso), foi perguntado ao coordenador se a instituição tem algum documento/regulamento que 
estabeleça normas para a elaboração dos PPCs dos cursos da EaD. 61,9\% dos entrevistados responderam que sua instituição não possui nenhuma norma. Questionados sobre quais documentos orientam a elaboração do PPC, e considerando que mais de uma resposta poderia ser assinalada, $86,9 \%$ informaram utilizar o Catálogo Nacional de Cursos, enquanto o Currículo de Referência Nacional da Rede e-Tec (CATAPAN; KASSICK \& OTERO, 2011) aparece como segundo documento mais utilizado para a criação dos cursos, com um percentual de $73,9 \%$.

Outras opções, como o Parecer do Conselho Nacional de Educação, as normas internas da instituição e os referenciais de qualidade do MEC, também foram citadas como documentos utilizados. Num rápido olhar sobre os documentos que servem de referência à elaboração do PPC, observa-se que apenas o Currículo de Referência Nacional da Rede e-Tec faz menção às questões pedagógicas que devem fundamentar, teórica e metodologicamente, o PPC.

Na questão sobre como ocorre o processo de seleção dos bolsistas para professor formador, $34,8 \%$ dos coordenadores informaram que realizam processo seletivo simplificado com chamada pública por meio de edital. Já $47,8 \%$ dos respondentes informaram que a escolha ocorre por indicação e/ ou convite a servidores da instituição e $13 \%$ deles informaram que o processo ocorre por indicação ou convite para professores externos à instituição.

Quanto ao processo de seleção do professor conteudista, o resultado não mostrou diferença significativa: processo seletivo simplificado com edital, 43,5\%; indicação/convite a servidores da instituição, 47,8\%, e indicação/ convite a não servidores da instituição, $4,4 \%$.

Por outro lado, sobre o processo de seleção de tutores presenciais e/ou a distância e o de coordenador de polo, os resultados apresentaram-se bem diferentes. Em 86,9\% das respostas, o processo de seleção para tutor ocorre por meio de edital público, enquanto, para coordenador de polo, o uso desse instrumento é de apenas $21,7 \%$. Os dados mostram ainda que, para coordenador de polo, em 43,5\% são indicados professores entre não servidores da instituição.

Em todos esses processos seletivos (de professor formador, conteudista e tutores), o que se observa é que o processo é regido pelo signo administrativo e não pedagógico, o que nos leva à necessidade de aprofundar estudos sobre o teor dos quesitos estabelecidos para a seleção dos recursos humanos. Assim, pode-se saber se nela está contemplada a questão do conhecimento da episteme relacional e da pedagogia cognitivista que deve sustentar a organização didática da EaD. 
Com relação às questões da seleção dos recursos humanos que atuam nos cursos de EaD, observa-se uma não referência a critérios de competência técnica específica, quer do professor conteudista, coordenador de polo ou tutores em EaD, corroborando aquilo que, implicitamente, afirmamos acima, que a EaD ainda é tratada à sombra do ensino presencial, pois, como lá, essas funções não são objeto de preocupação.

No que se refere ao controle de atividades desenvolvidas, foi perguntado com que frequência é realizada a avaliação do polo, de seu coordenador e dos tutores: $57,1 \%$ responderam realizá-la semestralmente, enquanto $14,28 \%$ informaram não realizá-la. Igualmente, também é necessário retomar esse ponto, indagando sobre as questões pertinentes à epistemologia e pedagogia que sustenta as atividades desenvolvidas.

\section{Coordenador de curso}

No estrato dos coordenadores de curso, foram enviados questionários para 136 coordenadores com retorno de cinquenta, sendo cinco da região Centro-Oeste; nove do Nordeste; onze da região Norte; quinze do Sudeste e dez do Sul.

No questionamento sobre como ocorre a divulgação da abertura de oferta ou reoferta do curso, havia a possibilidade de assinalar: edital, jornal, rádio, televisão, alto-falante nas ruas e materiais impressos distribuídos em locais estratégicos (panfletos, notas, comunicados). A opção "Outro" poderia ser preenchida livremente.

Apesar da diversidade de meios de divulgação possíveis, a maioria dos cursos de EaD está utilizando um pequeno número deles. Para saber a frequência com que cada tipo de meio de divulgação foi utilizado, foram contabilizadas as 129 citações dadas nas respostas. O edital foi o meio de divulgação mais comum (36,47\%), seguido por materiais impressos (17,83\%), rádio (15,50\%) e jornal (13,18\%). A internet foi citada na opção "Outros" em apenas quatro ocasiões, o que parece uma subutilização desse meio de divulgação gratuito (já que todas as instituições possuem um sítio na internet), principalmente tratando-se de cursos a distância que são baseados na rede.

Os resultados apontam que a utilização de apenas um meio de divulgação representou $40 \%$ dos entrevistados. Esse fato, associado ao de ser o edital o meio de divulgação mais citado para a publicização dos cursos ofertados e, considerando que essa sistemática se restringe à publicação em jornais que nem sempre atingem, satisfatoriamente, a população a que se destinam os cursos, leva-nos a pensar sobre a necessidade de reestruturar o processo de divulgação dos cursos a partir da diversificação de estratégias. 
Nessa questão, entendemos como fundamental uma diretriz da Secretaria de Educação Profissional e Tecnológica (SETEC-MEC) em mobilizar campanha educativa sobre a Rede e-Tec Brasil e sobre o significado da educação a distância, aproveitando os meios de comunicação para massificar as informações básicas e difundir os princípios da EaD.

Os coordenadores também foram arguidos sobre como ocorre a decisão de oferta de cursos. Essa pergunta possuía três opções de resposta: a) através da pesquisa de mercado; b) atendimento a solicitação dos municípios/ estado; e c) planejamento interno da instituição para expansão de cursos no estado. Dos respondentes, 32 deles, ou seja, 64\% informaram que utilizam apenas uma das três ações; doze (24\%) utilizam duas ações; e apenas seis (12\%) dos coordenadores informaram que utilizam as três ações.

Para verificar quais ações são as mais utilizadas para a tomada dessa decisão, foram contabilizadas as 74 citações. $O$ atendimento a solicitações de municípios e/ou estados foi citado 36 vezes (48,65\%); a pesquisa de mercado foi citada onze vezes (14,86\%); e o planejamento interno da instituição para expansão de cursos foi citado 27 vezes (36,48\%).

Ao confrontarmos as respostas dadas pelo coordenador geral com as dos coordenadores de curso, observa-se a contradição, neste ponto, com relação à decisão para a escolha e oferta de novos cursos e/ou reoferta. Nos depoimentos do coordenador geral, a opção é orientada, em primeiro lugar, pela demanda do mercado, evidenciando a sintonia com a necessidade da formação profissional e apontando a coerência da instituição formadora que leva em conta também as solicitações dos municípios e Estado, os quais, por sua vez, também seguem a necessidade demandada pelo processo produtivo. Já a maioria dos coordenadores de curso (64\%) afirma seguir apenas um dos critérios - a solicitação realizada pelos municípios e/ou estado -, ficando a pesquisa de mercado como a terceira opção seguida.

$\mathrm{Na}$ questão que buscou verificar quais as principais dificuldades enfrentadas pelos coordenadores na gestão dos cursos, aparece em primeiro lugar a falta de recursos humanos, pois a Rede e-Tec Brasil cresceu significativamente, o que não aconteceu com o número de pessoas envolvidas, do que resulta o não atendimento das demandas geradas, tendo em vista, principalmente, as peculiaridades próprias da EaD. Disso se conclui sobre a necessidade de abertura de concursos públicos para técnico administrativo, dentre outras funções, para garantia e continuidade dos trabalhos com qualidade.

No que tange ao questionamento sobre os procedimentos avaliativos institucionais, os coordenadores responderam que, ao final do semestre, as instituições avaliam índice de evasão de estudantes (IEE), índice de retenção (reprovação) por disciplina (IRD), índice de retenção do semestre (IRS), índice 
de sucesso (número de estudantes aprovados) (IEA), desempenho dos tutores (DT), desempenho dos professores formadores (DPF), e“Outro", que podia ser respondido livremente. Dos 47 coordenadores de curso que responderam a essa pergunta, 13 (27,3\%) informaram que calculam os seis índices, enquanto 12 cursos costumam calcular três índices. Apenas dois cursos (4,26\%) levantam somente um dos índices de desempenho acadêmico.

Para verificar quais índices são mais comumente utilizados pelos cursos, foram contabilizadas as 189 citações sobre os índices de desempenho acadêmico feitas pelos coordenadores de curso. $\mathrm{O}$ índice de evasão de estudantes foi o mais utilizado, sendo citado 42 vezes ( $22,2 \%$ do total), enquanto três índices foram citados 32 vezes (16,9\% das citações): índice de retenção (reprovação) por disciplina $(10,58)$; índice de sucesso (número de estudantes aprovados) (16,93\%); e desempenho dos tutores (16,93\%). O índice menos calculado foi o de retenção do semestre, citado por 20 cursos $(10,6 \%)$.

A análise acurada desses dados possibilita à equipe gestora dos cursos ofertados pela Rede e-Tec Brasil a orientação para a tomada de ações no sentido de corrigir desvios de percursos não só no que tange às questões administrativas e de gestão, mas, principalmente, no que diz respeito às questões da arquitetura organizacional dos cursos, uma vez que os índices de insucesso somam $49,73 \%$, contra os $16,93 \%$ de sucesso.

Constata-se, portanto, que nenhum dos entrevistados apontou para a correlação existente entre os índices de evasão, retenção e sucesso dos estudantes com os índices de desempenho de professores (formadores, conteudistas, tutores) e com a organização e mediação pedagógica, investigando se ela ocorre ou não, sob a perspectiva da episteme relacional e da pedagogia cognitivista - ponto que a sequência da pesquisa terá que aprofundar.

No que diz respeito à aprovação do Projeto Pedagógico do Curso (PPC), 46,81\% dos respondentes informam que tiveram seus projetos aprovados pela SEED (Secretaria de Educação a Distância) quando de sua aceitação através do edital número 01 de 2007. Os cursos apresentados posteriormente, e/ou que já sofreram alterações, devem ter seus projetos pedagógicos aprovados em suas instâncias institucionais.

\section{CONSIDERAÇÕES FINAIS}

A pesquisa, ainda em desenvolvimento, por meio dos dados preliminares levantados, permite antecipar algumas ações institucionais que devam ser tomadas a curto e médio prazo como garantia da qualidade necessária à Educação Profissional Técnica de Nível Médio na Modalidade a Distância ofertada pela Rede e-Tec Brasil. Entre elas: 
a) elaboração de quadro referência relativo ao número de profissionais necessários ao pleno funcionamento e desenvolvimento dos cursos, referência esta que deve tomar por base não apenas o número de matrículas por curso, mas também a diversidade de cursos ofertados pela instituição;

b) idêntico procedimento deve ser adotado com relação aos recursos físicos, tecnológicos, financeiros e didáticos;

c) contratação, através de concurso público, de recursos humanos necessários a cada instituição ofertante de cursos de acordo com o quadro referência e sob a perspectiva da epistem relacional e da pedagogia cognitivista;

d) oferecimento de curso específico a gestores, sobre a concepção pedagógica que deve fundamentar a $\mathrm{EaD}$, tendo em vista que eles respondem pelo funcionamento de todo o curso, desde a avaliação dos polos presenciais nos municípios, a formatação dos cursos, a seleção dos alunos, a produção do material didático, a assistência ao aluno, até a gestão financeira e todo o processo pedagógico, ou seja, planejamento, acompanhamento e controle;

e) oferecimento de cursos de formação específicos (para professores autores, formadores, tutores, técnicos) sobre a estrutura, funcionamento, tecnologia e principalmente sobre a episteme relacional e a pedagogia cognitivista que deve subsidiar a mediação pedagógica na EaD;

f) desenvolver metodologias para divulgação, nas diferentes mídias, da oferta de novos cursos;

g) no que tange à expansão numérica da oferta de cursos e/ou vagas, idêntico procedimento deverá ser tomado.

Essas ações, que preliminarmente podem ser apontadas, têm por objetivo garantir a democratização e interiorização da educação profissional técnica de nível médio, através da modalidade a distância, na perspectiva da epistem relacional e sua decorrente pedagogia cognitivista, como política inclusiva dos até então excluídos. 
INSTITUTIONAL MANAGEMENT OF DISTANCE EDUCATIONVOCATIONAL-TECHNICAL COURSES (HIGH SCHOOL LEVEL) OFFERED BYTHE “E-TEC BRASIL"NETWORK: FIRST INSIGHTS

AвSTRACT: In the last decade Brazil has invested heavily in Distance Education (DE). In 2007 the Escola Técnica Aberta do Brasil (Brazilian Open Technical School) was established, offering Vocational-Technical Courses (High School level) in the DE modality. This research of an exploratory nature, based on documental analysis and on the answers to a web quest sent to almost four hundred managers of such courses set out to discover how these courses are being implemented and managed nowadays. This study presents initial results which point to the main difficulties faced by management: lack of human resources (60.8\%), pedagogical support (43.4\%), physical infrastructure (34.7\%), financial resources (30.4\%) as well as difficulties arising out of the geographical spread of formation centers $(21.7 \%)$. (The questionnaire allowed for multiple answers). It also points out certain measures necessary for the consolidation and improvement of the quality of Vocational-Technical Courses (High School level) in the DE modality.

KEY WORDS: Reference curriculum. Vocational education. Distance education.

LA GESTIÓN INSTITUCIONAL DE LOS CURSOS TÉCNICOS PROFESIONALES DE NIVEL MEDIO EN LA MODALIDAD A LA DISTANCIA OFRECIDOS POR LA RED E-TEC BRASIL: PRIMERAS APROXIMACIONES

RESUMEN: A partir de la última década, Brasil ha realizado una gran inversión en la modalidad de Educación a Distancia. En 2007, se creó la Escuela Técnica Abierta de Brasil, que ofrece Cursos Técnicos Profesionales de Nivel Medio bajo la modalidad EaD. El enfoque propuesto por esta investigación, de carácter exploratorio, teniendo como instrumentos el análisis documental y los cuestionarios aplicados vía Web a 385 gestores de estos cursos, fue el de saber cómo está ocurriendo la gestión en el proceso de implantación y desarrollo de estos cursos. Este trabajo presenta los resultados parciales que apuntan las principales dificultades en la gestión: falta de recursos humanos $(60,8 \%)$, de apoyo pedagógico $(43,4 \%)$; de estructura física $(34,7 \%)$; de recursos financieros (30,4\%); así como la institucionalización de los polos $(21,7 \%)$, entre otros (el cuestionario admitía múltiples respuestas). La investigación apunta, aun, algunas de las medidas necesarias para la consolidación y calificación de la Educación Técnica Profesional de Nivel Medio, en la modalidad a distancia.

Palabras Claves: Currículo referencia. Educación profesional. Educación a distancia. 


\section{NOTAS}

1. Kassick (2012, p. 17) denomina de "arquitetura organizacional" a estrutura, organização, funcionamento e a inter-relação dos elementos constitutivos e presentes no espaço de convivência educativo, capaz de contribuir para a formação de subjetividades autônomas.

2. Segundo Latour (2001), actantes são todos os mediadores que integram o processo de interação, sejam eles humanos ou não humanos.

3. Juntamente a Becker (1993), entendemos o sujeito como Sujeito Cognoscente, e como Objeto tudo o que não é o Sujeito.

4. O sentido de "apreender", que tomamos de empréstimo de Anastasiou (2003, p. 14), significa aqui "o apreender, do latim apprehendere, que significa segurar, prender, pegar, assimilar mentalmente, entender, compreender, agarrar. Não se trata de um verbo passivo; para apreender é preciso agir, exercitar-se, informar-se, tomar para si, apropriar-se, entre outros fatores..." (grifado no original).

\section{REFERÊNCIAS}

ANASTASIOU, L. G. C.; ALVES, L. P. Processos de ensinagem na Universidade: pressupostos para as estratégias de trabalho em aula. Joinville, SC: UNIVILLE, 2003.

BECKER, F. A epistemologia do professor: o cotidiano da escola. Petrópolis: Vozes, 1993. BRASIL. Decreto n. 1.917 de 27 de maio de 1996. Aprova a estrutura Regimental e o quadro demonstrativo de cargos em comissão e funções gratificadas do Ministério da educação e do desporto e dá outras providências. Disponível em: <http://www .planalto. gov.br/ccivil_03/decreto/1996/D1917.htm>. Acesso em: 18 maio 2012.

. Lei n. 9.394 de 20 de dezembro de 1996. Estabelece as Diretrizes e Bases da Educação Nacional. Disponível em: <http://www.planalto.gov.br/ccivil_03/leis/L9394. htm>. Acesso em: 18 maio 2012.

Decreto n. 5.622 de 19 de dezembro de 2005. Regulamenta o artigo 80 da Lei n. 9.394 de 20 de dezembro de 1996. Disponível em: <www.planalto.gov. br/ccivil_03/_Ato2004.../decreto/D5622.htm>. Acesso em: 18 maio 2012.

. Decreto n. 5.800 de 8 de junho de 2006. Dispõe sobre o Sistema Universidade Aberta do Brasil. Disponível em: <http://www.planalto.gov.br/ccivil_03/_ato20042006/2006/decreto/d5800.htm>. Acesso em: 13 maio 2012.

Decreto n. 6.301 de 12 de dezembro de 2007. Institui o Sistema Escola Técnica Aberta do Brasil - e-Tec Brasil. Disponível em: <http://www.planalto.gov.br/ccivil_03/_ Ato2007-2010/2007/Decreto/D6301.htm>. Acesso em: 13 maio 2012.

Decreto n. 7.589 de 26 de outubro de 2011. Institui a Rede e-Tec Brasil. Disponível em: <http://www.planalto.gov.br/ccivil_03/_Ato2011-2014/2011/Decreto / D7589.htm>. Acesso em: 18 maio 2012. 
CATAPAN, A. H.; KASSICK, C. N.; OTERO, W. R. I. (Org.). Currículo referência para o sistema e-Tec Brasil. Florianópolis: NUP/UFSC, 2011.

CHIAROTTINO, Z. R. A teoria de Jean Piaget e a educação. In: PENTEADO, W. M. D. (Org.). Psicologia e ensino. São Paulo: Papel Livros, 1980.

CORRÊA, J. (Org.). Estruturação de programas em EaD. Educação a distância: orientações metodológicas. Porto Alegre: Artmed, 2007.

FREIRE, P. Concientización. Buenos Aires: Ediciones Busqueda, 1974.

KASSICK, C. N. A educação segundo os princípios da pedagogia libertária: A experiência da escola Paidéia de Mérida/Espanha - o que dizem os ex-paideianos? Anais do $54^{\circ}$ International Congress of Americanists. Áustria, Viena: Universidade de Viena, 2012.

LEME, R. A. Curso de estatística - elementos. Rio de Janeiro: Ao Livro Técnico, 1967.

LEVIN, J. Estatística aplicada às ciências humanas. São Paulo: Harper \& Row do Brasil, 1978.

LATOUR, B. A esperança de Pandora: ensaios sobre a realidade dos estudos científicos. Bauru: EDUSC, 2001.

MOORE, M. J. Conceitos básicos In: MOORE, M. J.; KEARSLEY, G. Educação a distância: uma visão integrada. São Paulo: Thompson, 2007.

MORAES, M.; GULARTE, D. S.; RODRIGUES, R. S.; CATAPAN, A. H.; MALMANN, E. M. Guia geral do curso - gestão e docência em EaD. Florianópolis: UFSC/UFSM, 2007.

PEREIRA, J. L. O cotidiano da tutoria. In: PEREIRA, J. L. et al. Educação a distância: orientações metodológicas. Porto Alegre: Artmed, 2007.

PIAGET, J. Comportamento motriz da evolução. Portugal, Porto: Res Ed. 1977.

. Psicologia e pedagogia. Rio de Janeiro: Forense Universitária, 1988.

ClOVIS NiCANOR KASSICK é doutor em Educação pela Universidade Estadual de Campinas (Unicamp). Professor aposentado da UFSC, atualmente atua na Universidade do Sul de Santa Catarina (Unisul), no curso de Pedagogia e no Programa de Pós-Graduação - Mestrado em Educação. Desenvolve pesquisa na área da gestão e organização de processos educativos, com enfoque especial na organização escolar libertária, cuja experiência vivenciou na Escola Paidéia de Mérida-Espanha. Desenvolveu pesquisa de pós-doutorado, como bolsista da Fundación Carolina de Madrid-Espanha, junto à Universidade de Valladolid, Valladolid/Espanha e à Universidade Técnica de Lisboa, Instituto Superior de Economia e Gestão. É pesquisador associado do Grupo de Investigación sobre desarrollo territorial sostenible, da Facultad de Educación y Trabajo Social de la Universidad de Valladolid-Espanha. 
É pesquisador do grupo GTMC-UFSC, na pesquisa: Elaboração de Currículos Referência para os Cursos Técnicos da Escola Técnica Aberta do Brasil/e-Tec Brasil, do E-TEC/SETEC/MEC, PCEADIS/CNPq.

E-mail: kassickclovis@smail.com

José SeVERINo Bento é doutorando em Etnobiologia/UFRPE, mestre em Biologia Animal pela Universidade Federal de Pernambuco (1999) e graduado em licenciatura em Ciências Biológicas pela Universidade Católica de Pernambuco (1996). Professor do Instituto Federal de Educação, Ciência e Tecnologia de Pernambuco (IFPE) do curso Superior de Tecnologia em Gestão Ambiental, com experiência nas áreas de Gestão Pública, Gestão de Áreas Protegidas e Educação Ambiental. Pesquisador do Grupo de Pesquisa - Currículo de Referência II, Linha de Pesquisa Gestão Institucional da $\mathrm{EaD}_{\mathrm{D}}$ do Fórum Nacional de Educação Profissional Técnica a Distância - FNEAD/UFSC e Rede e-Tec Brasil e PCEADIS/CNPq/FNDE.

E-mail: jb_bento@hotmail.com

Paulo Ricardo Santos Dutra é mestre em Nutrição, concentração em Ciência dos Alimentos, pela UFPE (2005), e graduado em Engenharia Agronômica pela Universidade Federal Rural de Pernambuco (1990). Atualmente, é professor da Universidade Federal Rural de Pernambuco. Tem experiência na área de Ciência e Tecnologia de Alimentos, com ênfase em Tecnologia de pós-colheita e na área de Controle de Qualidade de alimentos. É coordenador adjunto do Núcleo de Educação a Distância, que oferece atualmente o Curso Técnico em Alimentos, e coordenador adjunto da educação a distância pela Rede e-Tec Brasil desde 2008 (CODAI/UFPRE). Pesquisador do Grupo de Pesquisa Currículo de Referência II, Linha de Pesquisa Gestão Institucional da $E_{a} D$ do Fórum Nacional de Educação Profissional Técnica a Distância FNEAD/UFSC e Rede e-Tec Brasil e PCEADIS/CNPq/FNDE.

E-mail: dutrapaulo2008@hotmail.com 